\title{
USING SMART PHONES-BASED APPS, COMPUTER APPLICATIONS AND GEOGRAPHIC INFORMATION SYSTEM (GIS) IN REAL ESTATE PRACTICE
}

\author{
${ }^{1}$ Ifediora, Christian Osita and ${ }^{2}$ Efobi, Dumebi Jessica \\ ${ }^{1}$ Department of Estate Management, Ajayi Crowther University Oyo. \\ ${ }^{2}$ Department of Estate Management, Chukwuemeka Odumegwu Ojukwu
}

\begin{abstract}
The world has advanced technologically to the extent that information can be assessed anywhere around the globe in the comfort of ones living room. Moreso, with the coming of pandemic which also help advanced the course of online transaction, it becomes imperative to explore technological advancements that were made in order to navigate through those challenges. It is based on the above that this study explored the application of GIS vis-àvis the use of GCP/GPS, phone-based apps, google earth interface, and others on real estate practice. The study illustrated practical steps taken via the use of GCP/GPS as well as google earth interface. The findings indicated that GCP/GPS can be used to gather location information of properties/location whereas the google earth interface can be used to do a variety of things, including getting directions and distance of places as well as measurement of length/areas of land and landed properties. It is expected that the illustrations provided will further help professionals especially who are yet to embrace the new way of carrying out certain task in relation to real estate will aid them in their service delivery.
\end{abstract}

KEYWORDS: GCP, GIS, GPS, real estate, professional practice.

\section{INTRODUCTION}

The world is no doubt a global community and information dissemination is made easier with the advancement of technology and technological advancement. Kotlarsky and Oshri (2005) observed that technology is now in the forefront of the modern world, creating new jobs, innovations, and networking to allow individuals connect globally. Transaction in real estate is made much with improved technological innovation using instrument such as land information system (LIS), geographical information system (GIS) etc. GIS is the process of collection, organizing of huge data with geo-referenced, automated, spatial information system for analysis, monitoring and management of the entire system. The advent of GIS has no doubt led to improved transaction in real estate as well enhance professional practice.

The real estate sector no doubt is growing in leaps and bounds while clients are also growing also in terms of sophistication in their quest for access to global issues and transactions in the real estate sectors, their quest and desire to get best served and global services is growing by the day and there is need for professionals to respond to these growing concerns in terms of 
global best practice. To meet up with clients growing sophistication, it is important that options offered by GIS based technological advancement and service delivery is explored.

There is great need for practitioners to expand their knowledge of the use GIS to enhance their service delivery since the real estate sector is also contributing immensely to the built environment, providing millions of jobs. Hence, it has been observed that global construction output is expected to almost double to US $\$ 15$ trillion by 2025 , up from US $\$ 8.7$ trillion in 2012, emerging markets in Asia will be the fastest growing region, but sub-Saharan Africa is expected to be the second highest, PWC, (2014). Real estate sector, a part of the global construction industry has continued to attract capital and demonstrate its resilience as an investment asset class, (PricewaterhouseCoopers (PwC), 2017). Also, according to Bhaskar, Deshmukh and Aradhana (2016), in many developing countries, major construction activities account for about $80 \%$ of the total capital assets, $10 \%$ of the GDP, and more than $50 \%$ of the wealth assets invested in fixed assets. More than $50 \%$ of asset of most nations is held in real estate (Brown and Matysiak, 2000).

While transactions in real estate deals on location, GIS is also about space and location while emphasizing information gathering on spatial information and data analysis as well. GIS aims at information gathering about population gathering information, assembly of same and them further analysis for decision making. Based on the information analyses can be applied for advice to clients.

The increasing volume of transaction in real estate sector/professional practice as well as volume of data generated in the sector for further use in analysis and decision is an eye opener on the need to fully adopt GIS application to meet demands. With GIS, queries can be performed which gives users opportunity to ask specific question on location of real estate, area/size of the real estate (property), the type etc.

The importance of the application cannot be overemphasized or underestimated. It is important to further intimate practitioners on the wide range of opportunities offered by GIS for effective and efficient service deliver as well as global best practices. This paper offers practical illustration on application of GPS (GCP), and google earth in demonstrating how information on real estate (property) can be accessed. It is expected that practitioners will find the information relayed in this paper useful.

\section{LITERATURE REVIEW AND THEORETICAL FRAMEWORK}

This is specifically the theoretical framework upon which this paper is built. It centers on relevant ideas about GIS and its application in real estate. Definitions/meaning of apps applications, smart phones, GCP/GPS and google earth are captured in the review.

\section{SMART PHONES}

There has been several attempts aimed at defining smart phones, but this however shows that there is no consensus on the generally accepted definition. In trying to define Smartphone, Litchfield (2010) examined the top five most accepted definitions of smart phone, and 
Vol.10, No.1, pp. 32-45, 2022

ISSN 2054-6351 (print), ISSN 2054-636X (online)

concluded that there was no single, accepted definition. He opined that due to the constantly evolving nature of mobile phone technology, the line between "smart" and "dumb" phones is unclear. He argued that even "dumb" phones can have some "smart" phones' features, such as a touch screen and a proper operating system. He concluded that smart phones are phones that runs an open operating system and is permanently connected to the Internet. Litchfield noted that it is important to know the "smart features" on smart phone nowadays adding that today's smart phones, just like PCs, also incorporate operating systems which allow the add-on applications (or software) to run on top. Summarily smartphones are mobile phone that performs many of variety of functions of an operating system which is capable of running downloaded apps. It can be seen as a cell phone that includes additional software functions in its operation.

\section{APPS - APPLICATIONS}

Apps are basically seen as a mobile application, it is most commonly referred to as an app and is a type of application software designed to run on a mobile device, such as a smartphone or tablet computer. Mobile app are software applications that are developed for use on small, wireless computing devices which includes; smartphones and tablets other than personal computers - (Desktops, laptops and palmtops). Most mobile applications provide users with similar services to those accessed on PCs. These apps are generally small are mainly individual software units with limited function. They are designed with specifications while considering the demands and constraints of the devices in addition to taking advantage of any specialized capabilities they have. A mobile application also may be seen as an app, web app, online app, iPhone app or smartphone app. Mobile apps can be categorized into web-based apps or native apps as well as hybrid apps which combines element of both native and Web apps. Some of the apps used in this work are GPS Waypoints and Google earth. The icon or feature are as detailed;

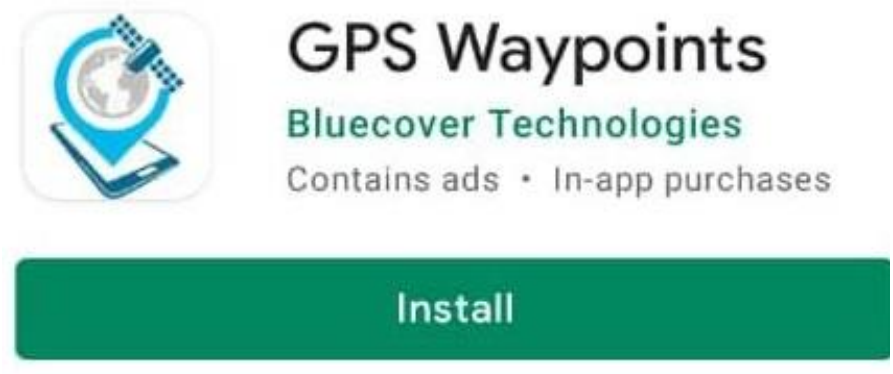

A typical GPS Waypoints icon on a smartphone

The above app is can be downloaded from Google play store. The basic features of the fully downloaded and installed GPS Waypoint has the following features; dashboard, satellite skyplot, Add waypoint, Start path, share location, north arrow or direction navigator, latitude, longitude and bearing, speed, accuracy etc. This shown in picture as follows; 


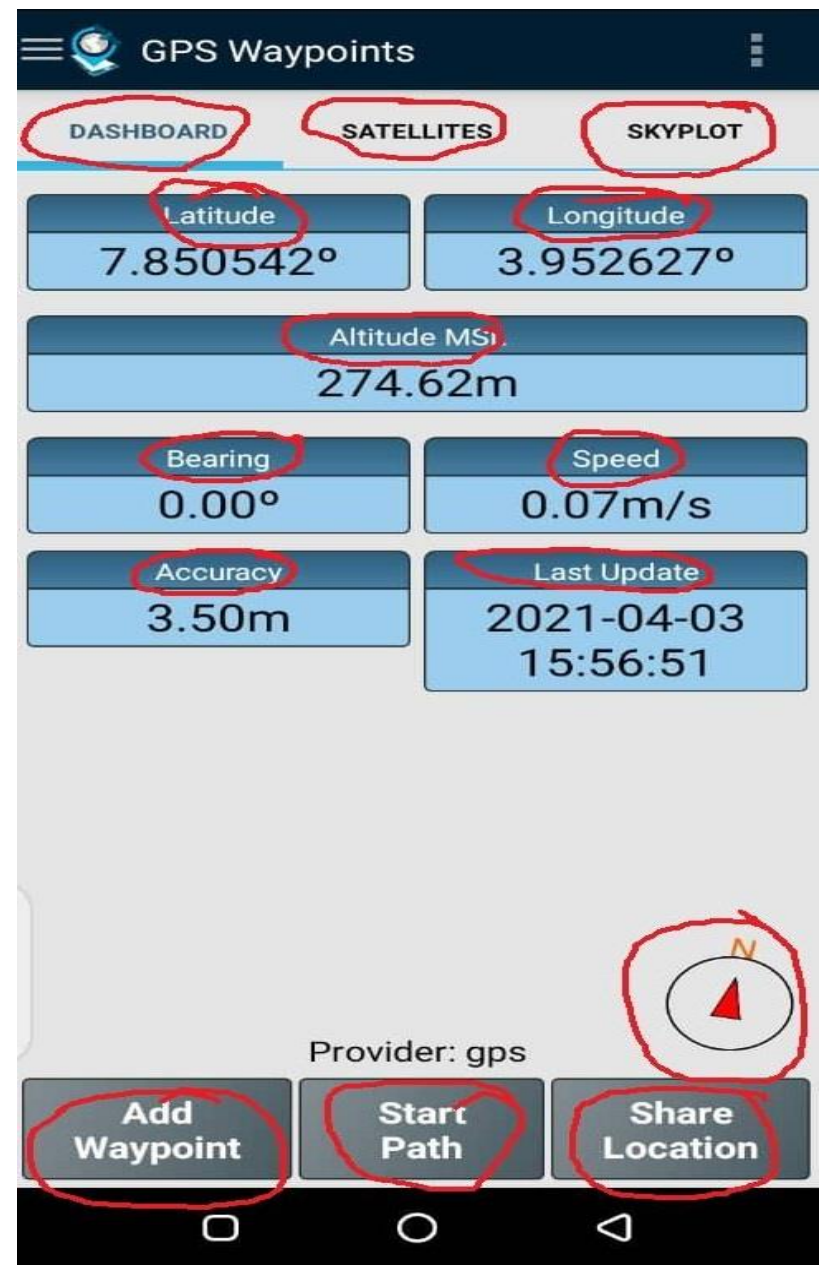

The dashboard shows;

- Latitude and Longitude indicates the location of your mobile phone.

- $\quad$ Altitude indicates the height of a mobile phone from mean sea level.

- Bearing and speed indicates the direction and speed on is travelling or moving.

- Accuracy indicates how accurate the longitude and latitude information on one's phone was updated.

The satellites shows list of satellite available like, satellite 4, 6, 7, 9, 14, etc., 0 GPS, 0 GLONASS, 0 other, 0 SBAS.

The skyplot is use to know satellites one is tracking and their position in the sky. Skyplot's visual and graphical screen helps in identifying when satellites are being masked by surrounding structures, trees and mountains. A skyplot is seen as an illustration of GPS satellite trajectories over a given GPS site (Marshall, 2002; Hilla, 2004). 
According to Gakstatter, (2015), NMEA means the National Marine Electronics Association. According to him NMEA existed well before GPS was invented. The intent was to give equipment users the ability to mix and match hardware and software. NMEA-formatted GPS data contributed to hitch free task performance by making software developers to write software for a wide variety of GPS receivers instead of having to write a custom interface for each GPS receiver. For example, Visual GPS Software which a free software accepts NMEAformatted data from any GPS receiver and graphically displays it.

Other visible features include;

- $\quad$ Add Waypoints.

- Start path and

- $\quad$ Share location.

\section{GIS - GCP/GPS}

Ground Control Points (GCPs) are defined as points on the surface of the earth of known location used to geo-reference Landsat Level-1 imagery. Return to Landsat Geometry Overview Search for Landsat Ground Control Points. The Landsat Ground Control Point Search allows you to extract ground control point binary files over your area of interest. (U.S. Department of Interiors - USGS).

GCP can be used to identify areas where solid waste is discharged/disposed, their locations, boundaries, even vehicular reports on disposal. They can be used to track drivers and know their exact locations. So, property managers, big time estate managers can deploy GPS to monitor movements of facilities like tankers meant to dispose of waste thereby avoiding the usual tricks and excuses of the drivers during the discharge of their duties.

According to Villanueva and Blanco (2018), one of the factors that can significantly improve the quality of the data products is the use of accurate and well-distributed Ground Control Points (GCPs) to tie down the model properly to the ground values. He added that to ensure both global and internal accuracy across datasets in different period, the location, distribution, and number of GCPs should be considered in establishing them in the area of interest.

Ground Control Point (GCP), information about a property/real estate can be made known such as;

1. Building name.

2. Owner's name.

3. Date of construction.

4. Roof type.

5. Ward number.

6. Drawing number.

7. Contractor name. 
8. Building type - residential, commercial, industrial etc.

With the help of high-resolution satellite data and drone survey data as well field surveys using GIS mapping can be done smoothly/easily. Properties can be uploaded, as well as building plans of each property details with attribute information can be obtained from GIS map.

GIS is also useful in querying - defaulters. Information about defaulters can easily be obtained. This will enable authorities to take action as at when necessary.

The interface of the GIS query can be performed. Popup will show the option of review property summary - total, residential (type), non-residential, current demand assessed and total revenue. Other features include type, property id, current demand tax not paid after and defaulters

\section{Global Positioning System}

GPS stands for Global Positioning System. It is a radio navigation system used in land, sea, and air to determine the exact location, time and velocity irrespective of weather conditions. The US military first used it in the year 1960 .

According to USDA, Maryland NRCS (2007), GPS is a positioning system based on a network of satellites that continuously transmit coded information. The information transmitted from the satellites can be interpreted by receivers to precisely identify locations on earth by measuring distances from the satellites. GPS is funded by and controlled by the U.S. Department of Defense (DOD). The system is called NAVSTAR - Navigational satellite timing and ranging.

GPS is a system and it is made up of three parts: satellites, ground stations, and receivers.

Following are the functionalities of each of these parts:

- $\quad$ Satellites act like the stars in constellations, and we know where they are because they invariably send out signals.

- The ground stations make use of the radar to make sure the satellites are actually where we think they are.

- A receiver is a device that you might find in your phone or in your car and it constantly seeks for the signals from the satellites. The receiver figures out how far away they are from some of them. Once the receiver calculates its distance from four or more satellites, it knows exactly where you are.

There are at least 4 GPS satellites in the line of sight of a receiver on the earth. The transmitter GPS sends information about the position and time to the receiver GPS at fixed intervals. The signals that are sent to the receiver devices are radio waves. By finding the difference in time between the signals sent from the GPS satellite to the time the GPS receivers, the distance 
between the GPS receiver and the satellite can be calculated. Using the trilateration process, the receiver locates its position as the signals are obtained from at least three satellites.

For a GPS to calculate a 2-D position, which includes the latitude and longitude, a minimum of 3 satellites are required. For a 3-D position that provides latitude, longitude, and altitude, a minimum of 4 satellites are needed.

\section{Google earth}

Information collection from Google earth is very crucial in real estate practice; this will not only help enhance the practice but will earn practitioners' confidence in the same. It has been helpful to users and I still being helpful to users. With this application, Clients will be settled and assured of best global practice and service delivery. This is particularly true as information derived is authentic and pleasing. Practitioners who are into land deals can easily get longitude and latitude information of properties/real estate or land they wish to dispose of. Google earth can be used to get the exact location pictures for clients. To measure distances of certain geographical areas is also possible in Google earth even without visiting the place.

The first step in gaining access to information on Google earth is to first download Google earth on one's PC or smart phone.

According to Ifediora, (2021), All one needs to do is to get the longitude and latitude information of the property, then search for it on Google earth and show the client or give the same client to search especially when it's established that the client can use same to search clients have been seen to be growing in sophistication in knowledge and application of technology.

A typical Google earth app icon looks like

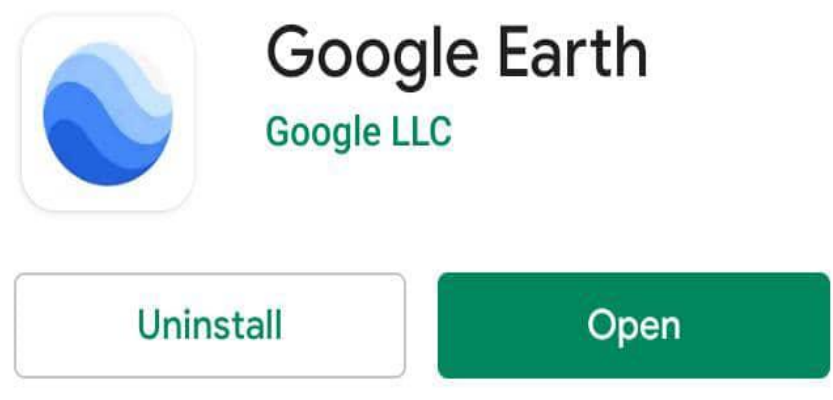

Google earth icon

The interface has several features with various symbols which are; 


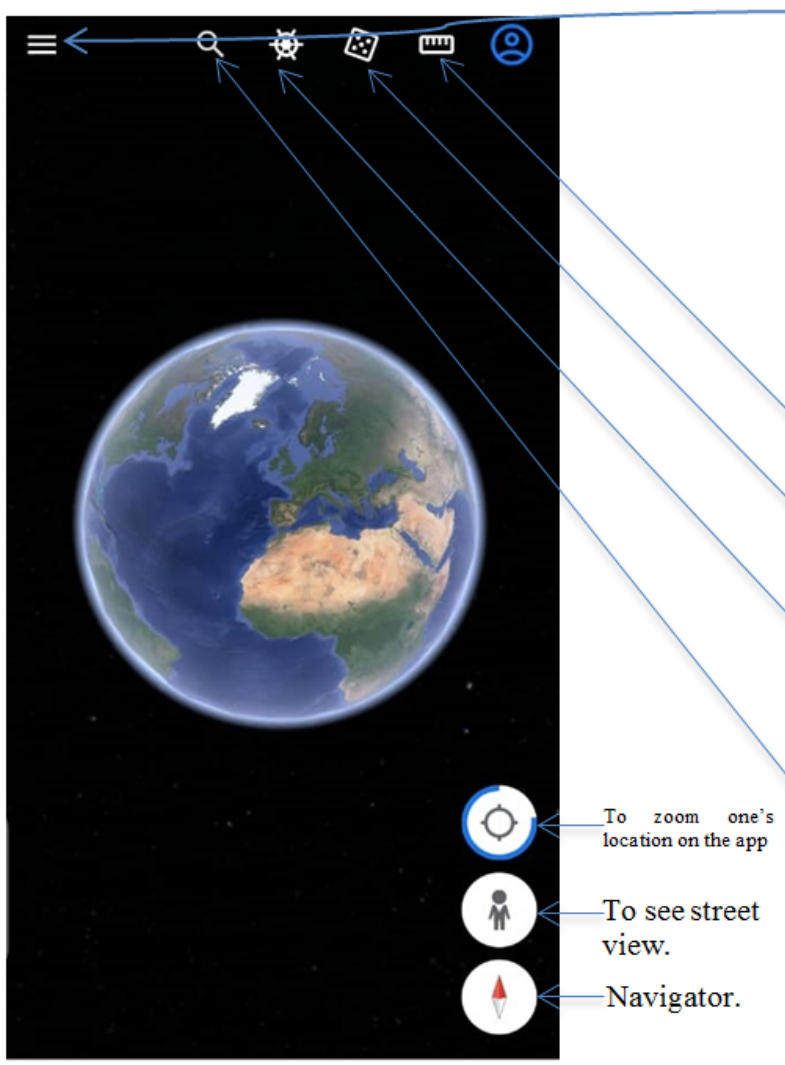

$\begin{array}{ll}\text { Indicates the following: } \\ \text { - } & \text { Voyager } \\ \text { - } & \text { Projects. } \\ \text { - } & \text { May style. } \\ \text { - } & \text { Photos. } \\ \text { - } & \text { Create postcard. } \\ \text { - } & \text { Share link and } \\ & \text { Settings. }\end{array}$

Ruler symbols for measurements which can be selected in various scales.

Used to view/show specific places, especially of interest by the apps.

Voyager - is a showcase of interactive guided tours, quizzes, and layers that aim to help educate everyone about the world. locations near and far.

For search, specific locations can be types here.

\section{MATERIALS AND METHODS}

This involves the practical illustrations on how various technological innovations can be used to further enhance real estate practice. It further shows or describes the step by step by which those innovations such as GCP/GIS and Google earth can be used to gather specific information relating to real estate, i.e. the practical illustrations based on theoretical discussions on how to go about a specific task using GCP/GPS and google earth.

\section{RESULTS AND DISCUSSION}

\section{GPS and Ground Control Point (GCP) - Using Smart Phone GNSS to collect latitude and longitude information of specific places/points on the earth surface}

The user is expected to do the following;

- Go to a particular point on the ground and stand for a few minutes. This is to enable you to achieve or get higher accuracy of that particular point on the earth to which one is standing for the purpose of getting latitude and longitude information.

- One can either write it down on a paper or screen shot it, for further reference in the studio/office. 
- It can be saved digitally by clicking Add Way Point, on the popup window, input GCP e.g. gcp1 as name, then save. This shows the location of the saved point.

- Then go to the dashboard and continue to gcp2 etc.

- One can as well create a path by using the start path option. It shows how you want to add points to your path, see options like $\odot$ Add points manually $\odot$ Add a point every second $\mathrm{x}$ second choose any, then ok.

- If chose $\odot$ Add a point every second x second. Add a point every x say, 10 seconds then ok. At window a new tab in the name of path will be added such as

Path (1): $0.00 \mathrm{~m}+0.00 \mathrm{~m} 0 \mathrm{~h} 0 \mathrm{~m} 0 \mathrm{~s}$

(1) $14: 06: 17$, Acc: $2.80 \mathrm{~m}$

- $\quad$ To finish recording, tap or click on the finish path. Tap on $\square$ Enclose the line to form a polygon, and then save. The project can be saved as DIST 01

- $\quad$ To open a saved file, go to file manager on phone storage and look for GPS way points that are usually in path.kml.

- If one uses Google earth on his mobile phone, he can open it by double clicking on it. Note that the above GCP and GNS process is a way to get the longitude and latitude information of an area that has none. With this longitude and latitude information one can register the ward_map and use it to perform georeferencing.

- $\quad$ Once the georeferencing is complete, save as Pro_image.

The implication of the result gotten from GCP way points, is that user have access or can get link of a particular location or property which can be sent to client. The client too is expected to be knowledgeable on the use of same. Once the link is available, one can open and view the location of the property in question and also have access to other information like adjoining properties, street name and address etc. where properties or land is located.

A typical link from GPS Waypoints looks like

GPSWpts-2021-10-09-path-bamidele.kml and the link when opened in Google earth is expected to show the path as seen in the picture labeled A1 below. 


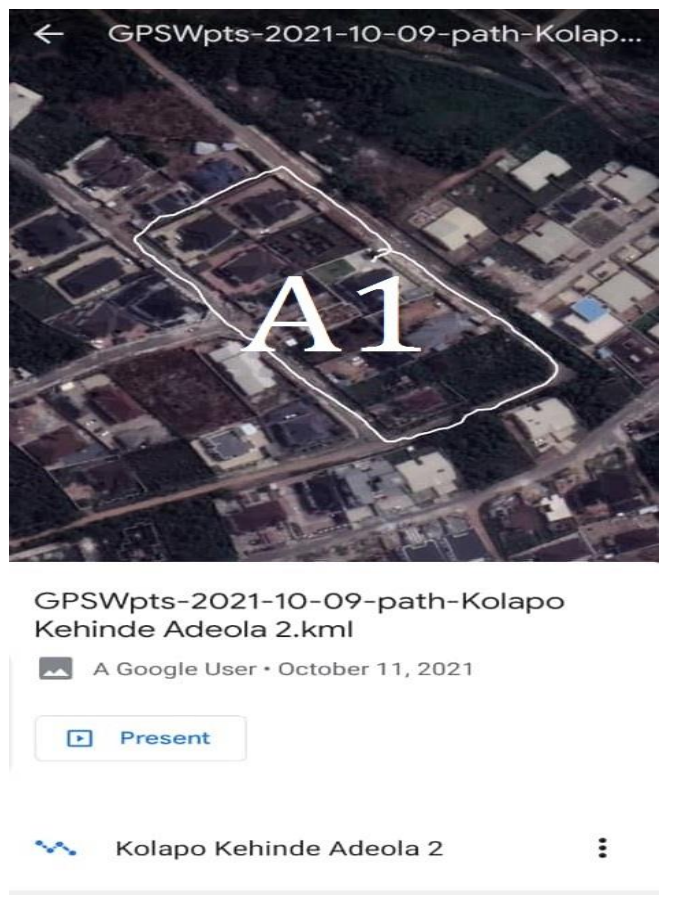

The picture showing the path.

With the path established as shown in the figure A1 above, one can actually take the measurement of the plots where the property (ies) are situated and even the longitude and latitude information of the place or location is shown.

\section{Google earth}

\section{Direction and distances of two points two places}

Measurement of distances of two places (points) in earth surface can all be done using Google earth apps installed in one's smart phone and as well personal computers. The steps are similar and require that one or user familiarizes him or herself with the app or software.

To do this one is to;

- $\quad$ Click on get direction input boxes A and B say Abuja to Lagos, Oyo to Ogbomosho etc. input say Abuja in box A and Lagos in box B. Click on get direction and search. This will show the route on the map as well the mode of transportation like car, train, walking and cycling.

- To see or hide roads and other information, one has to switch on and switch off their respective boxes at the layers option/panel and view the outcome. 


\section{Measurement of length/area of places}

1. One is to use the ruler tool on the toolbar, then zoom the place or location he or she wishes to measure and click on the ruler. On the popup, the user is expected to check out the options; lines, path, polygon, circle, 3D paths and 3D polygon.

2. Click on the line then go to Google earth interface, click and draw the lines on the points needed. The unit's measurement can be changed or rather adjusted to the desired type of unit say inches, meters, kilometers, feet, yards, degrees etc. One can save as required.

3. One can also clear the digitized area on the map by selecting the clear button.

NOTE: The

- $\quad$ Path button is the button used to create points on the Google earth interface.

- $\quad$ The polygon button is used to measure area e.g., one can use this to determine the size of an area seen on the interface. This means that an area can be measured using the same process without physically visiting the area.

- $\quad$ The 3D path is used to measure the height of the building.

- To see the 3D path, go to the search box, type and search the exact location you wish to measure and view the result.

- $\quad$ The 3D polygon is used to measure the area of the object. See Ajayi Crowther University, the polygon performed on the surface on Google earth interface window below with a view to determine the area labeled AJAYI CROWTHER UNIVERSITY POLYGON

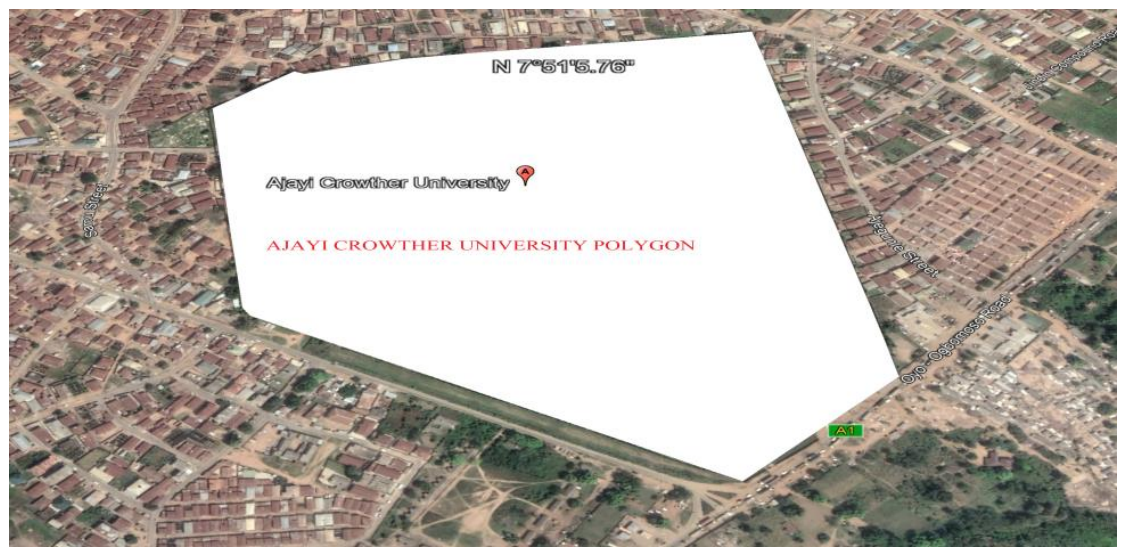

4. To see the real image of a feature such as a building, national monuments, tower etc. The image, which is circular in shape with three arrows and north direction on top, found at the right top of the display window can be used to view them. The 3D path can be used in this regard to view them. 
Vol.10, No.1, pp. 32-45, 2022

ISSN 2054-6351 (print), ISSN 2054-636X (online)

Samples of pictures derived from smart phone apps of Google earth showing the area and/or perimeter (distances) are shown in figures A, B and C.

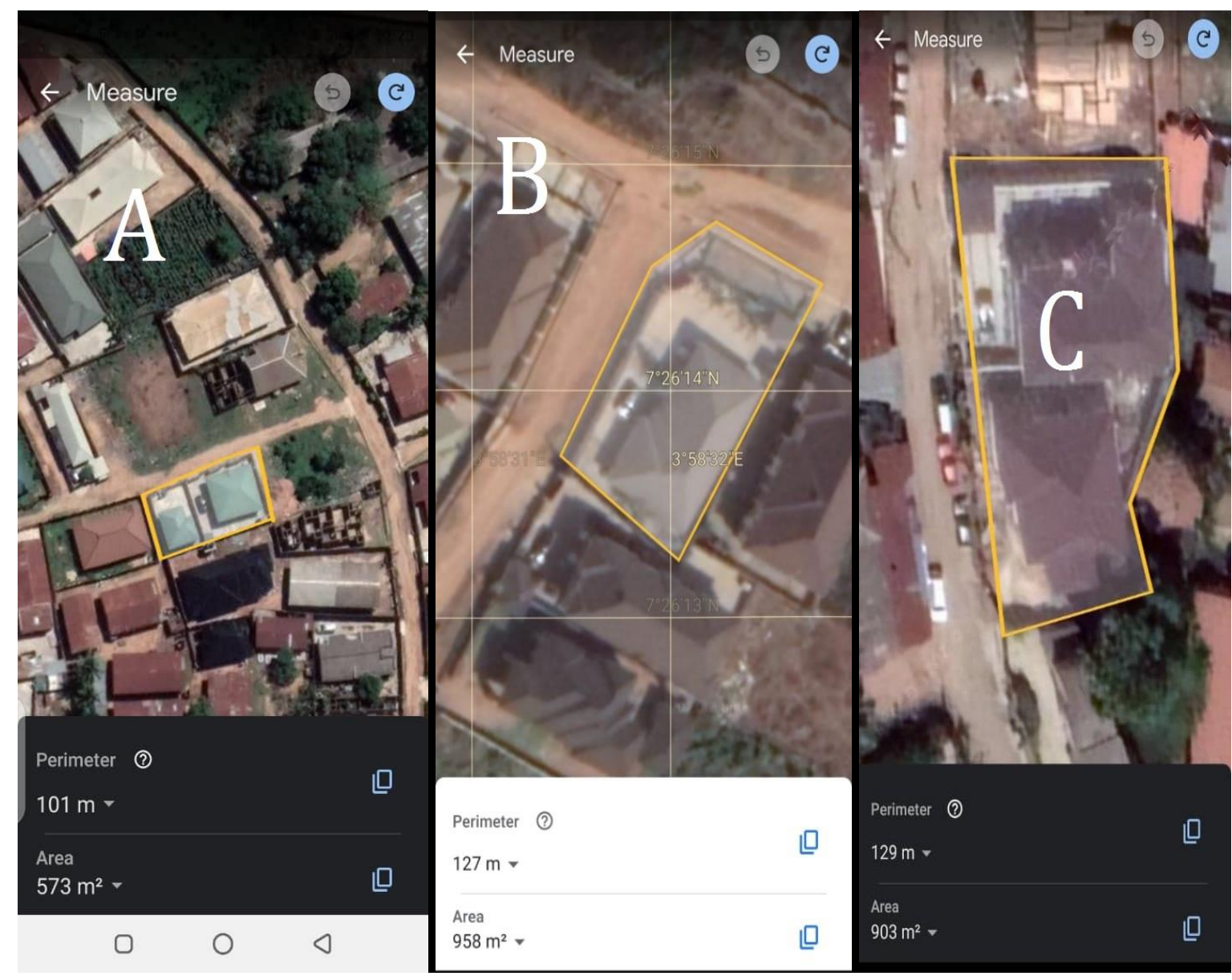

The areas or portion in yellow depicting various or different shapes are the areas of the property measured using Google earth app via smart phones.

\section{Temporal information of locations on earth surface using Google earth}

Here historical image option can be used to see temporal information, all one needs to do is;

1. Go to the view toolbar, click to activate historical imagery. A popup time internal will be displayed on the left side top of the interface (Google earth window).

2. Zoom the place you want to see the temporal information. Change the time interval of the satellite image on the bar. Here one can randomly zoom in on a place and the time interval to see development within/between one period and another.

3. Switch off the historical image window to view the window very well. 
Summarily, with google earth interface one can get information of specific places/location without visiting the place, take measurement of site or determine the area of place as illustrated with Ajayi Crowther University Oyo.

\section{CONCLUSION}

The advent of GIS no doubt has bridging the gap and it is still bridging same e.g. in case of communication especially in making it possible for clients to have pictorial view of the property/land that is up for sale (ready for transaction) or he is demanding at that point. It has in turn lessoned the burden requiring that clients physically visit the property, land or site he is interested in or need of purchasing.

With the aid of GCP/GPS, longitude and latitude information of place on earth surface or property can be derived and subsequent link sent to prospecting client to view. Also, with google earth interface, directions and distances of two points or places as well as measurement of same or more can be done at the comfort of one's home thus, making it easier for business to be done as well as checks on properties or query on properties. Other tasks can be performed in the Google earth, they are;

- $\quad$ Creation of points on the Google earth

- $\quad$ Showing elevation profile of the property or real estate.

- $\quad$ Saving image from Google earth

- Opening data from GCP/GNSS in Google earth.

It is expected that practitioners who are yet to explore this advancement should try their possible best to ensure that they avail themselves of the opportunities created by this technological improvement or advancement for greater and effective service delivery.

\section{REFERENCES}

Byjus, (ND) What is Global positioning system? Retrieved from https://byjus.com/physics/what-is-gps-global-positioningsystem/\#: :text=GPS\%20stands\%20for\%20Global\%20Positioning\%20System.\%20It \%20is,the\%20year\%201960.\%20Components\%20of\%20a\%20GPS\%20system

Doner, and Alkan R.M. (2010, September 23-24). Producing GIS aided real estate appraisal maps. International symposium on modern technologies, education and professional practice in geodesy and related fields. Varna, Albena Resort. https://www.researchgate.net/publication/335230646

Gakstatter, E. (2015). What Exactly Is GPS NMEA Data? Retrieved from https://www.gpsworld.com/what-exactly-is-gps-nmea-data/

Igwe. C., Oladejo, E. and Obodoh, C. (2017). Improving Property Management Using Geographic Information. System (GIS). A Case Study of Udoka Housing Estate, Awka, Anambra State, Nigeria. Developing Country Studies, 7 (8).

Ifediora, C.O. (2021). Application of GIS in real estate. ( $\left.1^{\text {st }} \mathrm{ed}\right)$. Awka, Kingstech Digital. 
Litchfield, S. (2010). Defining the smartphone. Retrieved from http://www.allaboutsymbian.com/features/item/Defining_the_Smartphone.php

Olaniyi, S.S., Udoh, E and Oyedare, B. A. (2006, October 8 -11). Application of GIS in Estate Management (A Case Study of Araromi Phase IV, Oyo. Nigeria). XXIII FIG Congress. Munich Germany

U.S. Department of Interiors - U.S. Government. Ground control point (GCP). Retrieved from https://www.usgs.gov/core-science-systems/nli/landsat/ground-controlpoints\#: :text=Ground\%20Control\%20Points\%20\%28GCPs\%29\%20are\%20defined $\% 20$ as\%20points,point $\% 20$ binary $\% 20$ files $\% 20$ over\%20your\%20area\%20of\%20inter est.

USDA, Maryland NRCS (2007). Introduction to Global Positioning Systems (GPS). Retrieved from https://www.nrcs.usda.gov/Internet/FSE_DOCUMENTS/nrcs144p2_024990.pdf

Villanueva, J.K.S. and Blanco, A.C. (2019). Optimization of ground control point (gcp) configuration for unmanned aerial vehicle (UAV) survey using structure from motion (SFM). The International Archives of the Photogrammetry, Remote Sensing and Spatial Information Sciences, GeoAdvance, 42 (10-11) Retrieved from https://www.int-archphotogramm-remote-sens-spatial-inf-sci.net/XLII-4-W12/167/2019/isprs-archives-

XLII-4-W12-167-2019.pdf 